\title{
Pseudomonas aeruginosa: caracterização antigênica e produção anticorpos
}

\author{
Diego Rodrigues Ribeiro ${ }^{{ }^{*}}$ \\ ${ }^{\text {a }}$ Universidade Federal do Tocantins (UFT), Brasil \\ *Autor correspondente (biomedicina@msn.com)
}

\section{N F O}

\section{Keyworks}

infections

multidrug resistant

vaccine

LPS

\section{Palavras-chaves}

infecções

multirresistentes

vacinal

LPS

\begin{abstract}
A B S T R A C T
Pseudomonas aeruginosa: antigenic characterization and antibody production

Pseudomonas aeruginosa has reduced over the years among infectious agents often isolated in hospital settings. Currently, nosocomial infections caused by $P$. aeruginosa pose a challenge for antimicrobial therapy. An alternative to the multiresistant microorganism was performed in search of vaccines. In this paper, check through the literature review or that there is concrete and the perspectives related to the characterization of $P$. aeruginosa antigens and by consequence of antibody production and applicability. Make a bibliographic survey in Portuguese and English periodicals from 1980 to 2019 and 19 works will be analyzed and inserted. In vaccination, available resources are based on antigens derived from virulence factor toxins known from $P$. aeruginosa species, such as; exotoxin-A, proteases and elastases, and components of LPS. There was a shortage in the literature regarding the subject. Research should be conducted on antigen characterization and by performing test production.
\end{abstract}

\section{R E S U M O}

A Pseudomonas aeruginosa destaca-se ao longo dos anos entre os agentes infecciosos frequentemente isolado em ambientes hospitalares. Atualmente as infecções hospitalares causadas por $P$. aeruginosa representam um desafio para a terapêutica antimicrobiana. Uma alternativa frente aos micro-organismo multirresistentes tem sido a busca de vacinas. O presente trabalho visa verificar através de revisão de literatura o que há de concreto e as perspectivas concernentes a caracterização de antígenos de $P$. aeruginosa e, por conseguinte a produção e aplicabilidade de anticorpo. Fez-se um levantamento bibliográfico em periódicos das línguas portuguesa e inglesa entre os anos 1980 a 2019 sendo analisados e inseridos no trabalho 24 obras. No âmbito vacinal, os recursos disponíveis se baseiam em antígenos oriundo de toxinas de fatores de virulência conhecidos de espécies de $P$. aeruginosa, tais como; exotoxina-A, proteases e elastases, e componentes do LPS. Notou-se uma escassez na literatura quanto a temática. Pesquisas devem ser conduzidas na caracterização de antígenos e por conseguinte produção de anticorpos. 


\section{INTRODUÇÃO}

O termo Bactérias Multirresistentes (BMR) tem sido empregado para designar um grupo de microrganismos resistentes a variedades de classes de antimicrobianos. BMR são patógenos envolvidos com infecções como pneumonias, septicemias, infecção urinária e meningite, especialmente em pacientes imunocomprometidos (Giamarellou et al., 2008), que foram hospitalizados por longos períodos e/ou passaram por procedimentos invasivos com uso prévio de medicamentos antimicrobianos (Castilho et al., 2017).

De importância clínica, pois causam infecções nosocomial oportunistas (Martins e Barth, 2013). Essas bactérias possuem uma habilidade de sobrevivência em uma variedade de condições ambientais persistindo por longos períodos em superfícies, o que gera uma frequente causa de surtos de infecção hospitalar (Fournier e Richet, 2006; Vieira e Picoli, 2015). Podem realizar a colonização em equipamentos hospitalares com a formação de biofilmes devido a ação das proteínas da membrana bacteriana externa A - OmpA (Choi et al., 2005; Vieira e Picoli, 2015).

A Pseudomonas aeruginosa destaca-se ao longo dos anos entre os agentes infecciosos frequentemente isolado em ambientes hospitalares. Diversos estudos têm associado sua presença a uma disseminação clonal da espécie. A despeito dos avanços tecnológicos e da variedade de antimicrobianos conhecidos, bilhares de anos de evolução conferiram a este microrganismo mecanismos naturais e adquiridos de resistência que frustram os recursos terapêuticos na atualidade (Neves et al., 2011; Pires et al., 2009; Figueiredo et al.,2007). Atualmente as infecções hospitalares causadas por $P$. aeruginosa representam um desafio para a terapêutica antimicrobiana, uma vez que frequentemente estes bacilos apresentam um amplo espectro de resistência a diferentes classes de agentes antimicrobianos através da aquisição de diversos mecanismos distintos de resistência (Silva, 2016).

A resistência intrínseca uma ampla variedade classes de antibióticos, é algo marcante na $P$. aeruginosa. Isso é um fator limitante a terapêuticas. Além disso embora antibióticos até possam estar disponíveis, a alta capacidade desse micro-organismo em desenvolver multirresistência a vários compostos, comprometendo o tratamento de pacientes, especialmente portadores de fibrose cística (Gavinho, 2011).

Uma alternativa frente os micro-organismos multirresistentes tem sido a busca de vacinas. Essa alternativa visa a prevenção das infecções causadas por diversos micro-organismos, dentre eles a $P$. $a e$ ruginosa, auxiliando na manutenção da saúde e qualidade de vida da população (Santo, 2009).

O estudo visa verificar através de revisão de literatura o que há de concreto e as perspectivas concernentes a caracterização de antígenos de $P$. aeruginosa e por conseguinte a produção e aplicabilidade de anticorpos frente esses antígenos.

\section{MATERIAIS E MÉTODOS}

Realizou-se um levantamento bibliográfico em periódicos das línguas portuguesa e inglesa entre os anos 2004 a 2019 nas bases de dados: Bibliografia Médica (MEDLINE) e Literatura Latino-Americana e do Caribe em Ciências da Saúde (LILACS). Esse período foi escolhido com objetivo de ter um panorama atual concernente a temática. Foram utilizados os descritores: Pseudomonas, $P$. aeruginosa, multirresistente, antígenos e anticorpos, e seus correlatos em inglês. Os critérios de inclusão foram: artigos de revisão e originais, assim como monografias, dissertações e teses. Foram analisados e inseridos no trabalho 24 trabalhos. Dois livros de relevância e a temática foram acrescidos como referência.

\section{RESULTADOS E DISCUSSÃO}

A $P$. aeruginosa pertence à família Pseudomonadaceae, apresenta-se como bastonete Gram-negativo reto ou ligeiramente curvo, aeróbio estrito, podendo se apresentar como células isoladas, aos pares, ou em cadeias curtas, móvel através de flagelo polar monotríqueo (Ferreira, 2005).

Cultivos de $P$. aeruginosas produzem uma variedade de colônias com diversas morfologias, embora dois tipos sejam mais comuns em meios de cultura: colônias de tamanho grande, com bordas lisas e elevação no centro e colônias pequenas, rugosas e convexas. Um terceiro tipo de colônias, de aspecto mucoide é ainda comumente observado em isolados de secreções respiratórias e urinárias (Silva, 2016).

Usualmente apresentam brilho metálico, com ou sem o odor frutal característico, decorrente da produção de trimetilamina. Não crescem em condições de acidez e apresentam crescimento ótimo em temperatura de $37^{\circ} \mathrm{C}$, além de exibir a capacidade de crescer a $42^{\circ} \mathrm{C}$, o que a distingue de todas as outras espécies do seu gênero. No que tangem sua exigência nutricional, crescem em meio mínimo, sendo capaz de utilizar um único composto orgânico como fonte de carbono e energia, mas também em meios enriquecidos, utilizam uma gama de fontes de carbono (Murray et al., 2010; Todar, 2012).

Pires et al. (2009) realizou um estudo retrospectivo baseado nos registros e laudos de culturas de 
secreções, onde $P$. aeruginosa foi o microrganismo mais frequente, estando presente em um total de $182(26 \%)$ das 701 amostras que apresentaram crescimento bacteriano. Concernente à origem, a $P$. aeruginosa foi isolada principalmente de infecções respiratórias provenientes de secreções traqueais e nasais. Os antimicrobianos mais eficazes contra a $P$. aeruginosa foram; amicacina, imipenem, meropenem e aztreonam.

Embora diversos trabalhos atribuam o alto perfil de resistências as enzimas inativadoras de antimicrobianos, existem outros mecanismos moleculares que conferem resistência, tais como; a perda de proteínas de membrana (porina OprD), ou até mesmo a superexpressão de bombas de efluxo (Dini, 2016).

A sua virulência, a $P$. aeruginosa apresenta um arsenal diversificado de mecanismos que contribuem na patogênese do processo infeccioso dependendo do sítio e tipo de infecção (Todar, 2012). Dentre esses eles as adesinas representadas pelos flagelos, fímbrias e o alginato, assim como mecanismos que promovem o rompimento celular e interferem no sistema imunológico como elastase, protease alcalina, fosfolipase C. Além disso esse micro-organismo é capaz de formular exoprodutos como a exotoxina A e os pigmentos (Silva, 2016). Os pigmentos fluorescentes formulados por essa bactéria, geralmente se difundem no meio de cultura, apresentam cores variadas, a saber, a pioverdina (esverdeado) e a piocianina (azulado), sendo que algumas estirpes formulam outros tipos de pigmentos, tais como; avermelhado (piorrubina) ou preto (piomelanina) (Ferreira 2005).

Segundo Meirelles (2011) a efetividade de fatores de virulência da $P$. aruginosa está vinculado a sistemas especializados de secreção. Há três tipos (I, II e III) bem caraterizados. O tipo I é o menos complexo de todos, composto essencialmente por um transportador do tipo ABC, uma proteína de fusão membranar e uma proteína de membrana externa, a protease alcalina é secretada dessa forma. O tipo II apresenta maior sofisticação, processando a secreção em dois estágios; primeiramente um substrato é transportado até o espaço periplasmático, e depois é transportado através de um poro para o meio extracelular; a elastase e exotoina A (ExoA) são secretados dessa forma. Já o sistema de secreção tipo III envolve a secreção do substrato diretamente do citoplasma da célula bacteriana para a o citoplasma da célula hospedeira, como os fatores são injetados diretamente no citoplasma da célula hospedeira eles são denominados de proteínas efetoras.

Os anticorpos denotam um grupo de moléculas que apresentam alta especificidade tanto para o reconhecimento como para inativação de substâncias externas, tais como moléculas tóxicas ou antígenos.
Anticorpos específicos, policlonais ou monoclonais, para diagnóstico, pesquisa e terapias tem sido obtido especialmente de mamíferos tais como coelhos e ratos (Tavares et al., 2013). Batista et al. (2019) os anticorpos são ferramentas biotecnológicas de alto valor, representando o segmento de maior crescimento no mercado de produtos biológicos alcançando atualmente.

Kronborg et al. (1992) relataram aumento sérica de $\operatorname{IgG}$, IgM e IgA ao lipídeo A, R-LPS e S-LPS durante o curso da infecção crônica, principalmente IgG e IgA. West et al. (2002) relatou em seu trabalho significativos de anticorpos contra lisado celular e ExoA foram detectados antes ou simultaneamente ao primeiro isolado de $P$. aeruginosa.

No âmbito vacinal, os recursos disponíveis se baseiam em antígenos oriundo de toxinas de fatores de virulência conhecidos de espécies de $P$. aeruginosa, tais como; ExoA, proteases e elastases. Pesquisas vem considerando a criação de vacinas conjugadas, incorporadas de proteínas e carboidratos, ou até mesmo vacinas recombinantes. Vacinas conjugadas vêm buscando conjugar o LPS de $P$. aeruginosa com toxóide tetânico. $\mathrm{O}$ toxóide tetânico, derivado da neurotoxina quimicamente inativada de Clostridium tetani, comporta-se como proteína carreadora, sem comprometer a resposta imune ou causar efeitos adversos (Gavinho, 2011).

O principal componente pró-inflamatório da membrana celular das bactérias Gram-negativas é o lipopolissacarídeo (LPS). Este tem sido um alvo antigênico importante para a resposta imune. Contudo, as vacinas produzidas a partir de células inteiras inativadas ou compostas apenas pelo LPS da célula bacteriana, conferem somente proteção temporária. Esse antígeno induz a produção de anticorpos por linfócitos B em uma via independente de linfócitos T-auxiliares, sem a geração de linfócitos de memória (Santos et al., 2011).

O reconhecimento do LPS é mediado pelo TLR4 (Toll-like recepctor 4 ), sendo que a $P$. aeruginosa tem a habilidade de modular a estrutura de seu LPS ao invadir o tecido hospedeiro visando driblar o sistema imune e manter a integridade da membrana externa. O desenvolvimento de uma vacina efetiva para $P$. aeruginosa não é novidade embora não seja algo que seja eminente, em primeira instancia ao problema relacionado a porção antigênica mais efetiva da superfície ser altamente variável, podendo ocasionar respostas cruzados e reações adversas (Santos, 2009).

Moss et al. (2001) valendo-se da técnica Western blot, encontraram a presença de anticorpos contra as proteínas do SSTT, sendo que em torno de $70 \%$, $90 \%$ e $67 \%$, dos pacientes tinham níveis aumentados de IgG anti-PopD, anti-PopB e anti-PcrV, respectivamente. 
Souza et al. (2012) na tentativa de determinar se anticorpos contra o LPS de $P$. aeruginosa em crianças seriam detectáveis antes do isolamento da bactéria em culturas de secreções respiratórias, observou que houve uma relação inversa entre as idades médias e a especificidade do IgG. Além disso a detecção da bactéria por cultura tendeu a acontecer antes do aumento de IgG, e a sorologia somente foi capaz de discriminar pacientes positivos e negativos antes da cultura em crianças entre 2 e 4 anos de idade.

Brett et al. (1988), ao utilizar ELISA afim de detectar anticorpos contra antígenos da parede celular, de pacientes com fibrose cística, aferiram elevação nos níveis de $\operatorname{IgG}$ quase dois anos antes do primeiro isolamento de $P$. aeruginosa em cultura.

Alternativas de imunoconjugados visando produção de anticorpos seriam; fragmentos polivaltentes do LPS ou de alginato conjugados a exotoxina A de espécies de Pseudomonas. Além disso, estudo com alginato conjugado ao toxoide tetânico tem demonstrado efetiva proteção em camundongos (Santo, 2009).

Em estudo longitudinal, Tramper-Standers et al. (2013), monitoraram a resposta de $\operatorname{IgG}$ à ExoA, ELA e PA de 220 pacientes durante três anos consecutivos, evidenciou que os testes sorológicos, individualmente, discriminaram bem a presença e ausência e de colonização crônica por $P$. aeruginosa.

\section{CONCLUSÕES}

Notou-se uma escassez na literatura quanto a temática. A maioria dos trabalhos com Pseudomonas aeruginosa enfoca em seu perfil de resistência e na caracterização do processo de patogênese. No que tange a produção de anticorpos e caracterização antigênica os poucos trabalhos conduzidos visam trabalhar com o LPS. Pesquisas devem ser conduzidas na caracterização de antígenos e por conseguinte produção de anticorpos.

\section{REFERÊNCIAS BIBLIOGRÁFICAS}

Batista JCL, Souza AR, Serra PT, Farias DS. Alves KCS, Almeida MEM, Glória JC, Castro DP, Mariúba AM. Tecnologia IgY: eficiente alternativa aos anticorpos convencionais de mamífero1. Scientia Amazonia, v.8, n.1, p.44-55, 2019.

Brett MM, Ghoneim ATM, Littlewood JM. Prediction and diagnosis of early infection in cystic fibrosis: a follow-up study. J Clin Microbiol, v. 26, n.1, p. 1565-70, 1988.

Castilho SRA, Godoy CSM, Guilarde AO, Cardoso JL, Andrea MCP, Junqueira-Kipnis AP et al. Acinetobacter baumannii strains isolated from patients in intensive care units in Goiânia, Brazil: Molecular and drug susceptibility profiles. PLoS. ONE, 2017.

Choi CH, Lee EY, Lee YC, Park TI, Kim HJ, Hyun SH, et al. Outer membrane protein 38 of Acinetobacter baumannii localizes to the mitochondria and induces apoptosis of epithelial cells. Cell Microbiol., v.7, n.8, p.1127-38, 2005.

Dini VSQ. Análise da resistência antimicrobiana em cepas de Pseudomonas aerugionsa isoladas em Unidade de Tratamento Intensivo em Manaus. 2016. 136 p. Dissertação (Mestrado em Biotecnologia) Universidade Federal do Amazonas, Manaus.

Ferreira LL. Estrutura clonal e multirresistência em Pseudomonas aeruginosa. 2005. 99 p. Dissertação (Mestrado em Vigilância Sanitária). INCQS, Rio de Janeiro.

Figueiredo EAP et al. Pseudomonas aeruginosa: Frequência de Resistência a Múltiplos Fármacos e Resistência Cruzada entre Antimicrobianos no Recife/PE*. RBTI, v. 19, n. 4, p. 421-427, 2007.

Fournier PE, Richet H. The Epidemiology and Control of Acinetobacter baumannii in Health Care Facilities. Healthcare Epidemiology. 42, 2006.

Gavinho B. Desenvolvimento de imunógeno bacteriano de Pseudomonas aerugionsa conjudado ao toxóice tetânico. 2011. 51 p. Dissertação (Mestrado em Microbiologia, Parasitologia e Patologia) Universidade Federal do Paraná, Curitiba.

Giamarellou H, Antoniadou A, Kanellakopoulou K. Acinetobacter baumannii: a universal threat to public health? Int J Antimicrob Agents, v.2, n.32, p.106-19, 2008.

Kronborg G, Formsgaard A, Galanos C, Freudenberg MA, Høiby N. Antibody response to lipid A, core, and O sugars of the Pseudomonas aeruginosa lipopolysaccharide in chronically infected cystic fibrosis patients. J Clin Microbiol, v.30, n.7, p.1848-55, 1992.

Martins AF, Barth AL. Acinetobacter multirresistente - um desafio para a saúde pública. Scientia Medica. v.23, n.1, p.56-62, 2013.

Meireles DA. Estudo da função do gene kerV de Pseudomonas aeruginosa. 2011. 187p. Tese (Doutorado em Bioquímica). Universidade de São Paulo, São Paulo.

Moss J, Ehrmantraut ME, Banwart BD, Frank DW, Barbieri JT. Sera from adult patients with cystic fibrosis contains antibodies to Pseudomonas aeruginosa type III apparatus. Infect Immun, v.69, n.1, p.1185-8, 2001.

Murray PR, Rosenthal KS, Pfaller MA. Microbiologia medica. 6 ed, Rio De Janeiro, Elsevier, cap 33, 2010.

Neves PR, Mamizuka EM, Levy CE, Lincopan N. Pseudomonas aeruginosa multirresistente: um problema endêmico no Brasil. J Bras Patol Med Lab, v.47, n.4, p.409-420, 2011.

Pires EJVC, Silva Júnior VV, Lopes ACS, Veras DL, Leite LE, Maciel MAV. Análise epidemiológica de isolados clínicos de Pseudomonas aeruginosa provenientes de hospital universitário. Rev Bras Ter Intensiva, v.21, n.4, p.384$390,2009$.

Santos RR. Desenvolvimento e estudo in vivo de uma vacina conjugada contra Pseudomonas aeruginosa. 2009. 51 p. 
Dissertação (Mestrado em Microbiologia, Parasitologia e Patologia) Universidade Federal do Paraná, Curitiba.

Santos RR, Caron LF, Gonçalves MLL, Sierakowski MR, Ferreira CEO, Ono L. Obtenção e caracterização de imunógeno conjugado de lipopolissacarídeo de Pseudomonas aeruginosa e albumina bovina. Arq. Inst. Biol., v.78, n.4, p.479-484, 2011.

Souza HA, Costa LM, Riedi CA, Maestri AC, Rosario NA. O diagnóstico sorológico pode detectar a colonização por Pseudomonas aeruginosa mais rápido do que as culturas em crianças com fibrose cística? Um estudo de coorte prospectivo. RBAC, v.44, n.2, p.70-6, 2012.

Silva ST. Análise fenotípica e genética de fatores virulência de isolados clínicos de Pseudomonas aeruginosa multidroga-sensível e multidroga-resistente de Recife-PE. 2016. 69 p. Dissertação (Mestrado em Medicina Tropical). Universidade Federal de Pernambuco, Recife.

Moss J, Ehrmantraut ME, Banwart BD, Frank DW, Barbieri JT. Sera from adult patients with cystic fibrosis contains antibodies to Pseudomonas aeruginosa type III apparatus. Infect Immun, v.69, n.1, p.1185-8, 2001.

Tavares TCF, Soares PM, Neves JHFF, Soares MMF, Junior Á, Souza DLN, Ávila VMR, Lima-Ribeiro AMC. Produção e purificação de imunoglobulinas Y policlonais antiLeptospira spp. Pesq. Vet. Bras. v.33, n.9, p.1097-1102, 2013.

Todar K. Todar's online Textbook of bacteriology. 2012.

Vieira PB, Picoli SU. Acinetobacter baumannii Multirresistente: Aspectos Clínicos e Epidemiológicos. R bras ci Saúde, v.19, n.2, p.151-156, 2015.

West SE, Zeng L, Lee BL, Kosorok MR, Laxova A, Rock MJ, et al. Respiratory infections with Pseudomonas aeruginosa in children with cystic fibrosis: early detection by serology and assessment of risk factors. JAMA, v.287, n.1, p. 2958-67, 2002. 